Colloque C3, suppl. au Journal de Physique III, Vol. 1, octobre 1991

\title{
DEVELOPMENT AND APPLICATXON OF HIGH STRAIN RATE CONSTITUTIVE MODELS IN HYDROCODES
}

\author{
P.D. CHURCH and I. CULLIS \\ DRA Military Division, ET2 Group, Building Q14, RARDE, \\ Fort Halstead, Sevenoaks, Kent TN14, Great-Britain
}

\section{RESUME}

Un prêrequis à la modélisation mécanique liée au dimensionnement d'ogives nucléaires et aux concepts correspondants est une compréhension fondamentale des réponses des matériaux sous des chargements très variés, allant du comportement élastique aux comportements plastique et hydrodynamique. Cet article décrit le développement et la mise en oeuvre au R.A.R.D.E. de lois de comportement améliorés prenant en compte les grandes vitesses de déformations pour une utilisation dans les hydrocodes. Les modeles déduits de la physique sont à même de décrire le comportement en déformation observé, et sont basés sur les travaux d'Armstrong et Zerilli. Ce modèle a été modifié et les paramètres identifiés pour les matériaux étudiés au RARDE à la fois dans leur état vierge et leur état choquée.

L'importance de disposer d'un modèle semi-empirique (par ex. Johnson-Cook) est mise en évidence. L'utilisation originale d'hydrocodes en simulation d'essais de caractérisation donne un point de vue supplémentaire à la méthode d'analyse employée pour l'identification du modèle de comportement. Nous présentons des résultats qui fournissent une preuve irréfutable de la validite du modèle d'Armstrong-Zerilli pour un acier pur dans l'espace vitesse de déformation-déformation-températures pour les matériaux impactés ou par l'application réussie de ce modèle à la formation d'un projectile par charge explosive est aussi démontrée.

\section{ABSTRACT}

A pre-requisite to the numerical modelling of warhead designs and concepts is a basic understanding of bow materials behave under various loads, ranging from elastic to plastic through to hydrodynamic. This paper describes the development and application at RARDE of improved high strain rate material models for use in hydrocodes. These physically derived models are capable of describing the observed deformation behaviour and are based on the work of Armstrong and Zerilli. This model has been modified and constants derived for RARDE based material, both unshocked and shocked.

The importance of having a physically based constitutive model, as opposed to a purely semi-empirical type model (e.g Johnson-Cook) is illustrated. The novel use of the hydrocodes in the simulation of the experimental material tests is shown to provide an extra insight into the method of analysis used in the derivation of a constitutive model. Results are presented which provide powerful evidence of the validity of the Armstrong-Zerilli model for pure iron in the high strain-rate, strain, and temperature regimes for both unshocked and shocked material. The successful application of this model to explosively formed projectile formation studies is also illustrated.

\subsection{INTRODUCTION}

During the past 10 years the use of hydrocodes to study problems associated with dynamic material deformation at high rates of strain has greatly expanded. Many different Eulerian and Lagrangian numerical schemes have been developed to simulate problems associated with various flow regimes.

In metal explosive interactions the material can deform at strain rates up to $10^{6}$ per second and reach temperatures in excess of $900 \mathrm{~K}$ and effective strains of well over 2.5 . Clearly the success of these simulations is strongly dependent on the constitutive relation used in the calculation.

The description of the complex material deformation path under these conditions must therefore account for the condition of the material after the passage of strong shock waves, as well as its strain hardening, strain rate, thermal softening behaviour. This description must also attempt to take into account structural effects such as grain size. As an example in the case of iron, a strong shock wave radically alters the microstructure by introducing significant twinning within the grain boundaries, increasing its hardness by a factor of $300 \%$. 
Recent research at RARDE, as part of the Independent European Programme Group ( IEPG ) activities on explosively formed projectiles, with soft iron bas led to the development of such an improved material algorithm. The aim of this research is to try and relate obeserved mechanical behaviour with material microstructure. This paper describes the use of theoretical modelling to simulate material tests, to identify the validity of this model at high strain, strain rates and temperature, and its subsequent application in explosively formed projectile design. The algorithm presented is based on the work of Armstrong and Zerilli (ref 1) and the experimentally determined material behaviour. The importance of having a physically based constitutive model, as opposed to a purely semi-empirical type model (e.g Johnson-Cook) is also illustrated.

\subsection{Material Algorithm Development}

The material used in this study was a pure iron commercially available as Remko. It was selected because of its well known metallurgical behaviour and supply to a consistent chemical specification. In addition there is extensive experience at RARDE for processing the material into a predetermined consistent condition. The material produced for this work had an average grain size of $35 \mathrm{~lm}$ and a hardness $\left(\mathrm{Hv}_{10}\right.$ ) of $74 \pm 1.3$ and was given the designator AQ85.

As is well known the interaction of a detonation wave with a soft iron generates a heavily twinned microstructure. This deformation mode is preferred since it represents the minimum energy path for the material to accommodate the large strains associated with the shock wave. Since the liner material in an explosively formed projectile warhead will be pre shocked before it deforms the characterisation of its properties is crucial for a successful material algorithm.

Goldthorpe ( ref 2 ) therefore, performed a series of detailed experiments on unshocked and shocked AQ85. These tests included tensile tests at strain rates from $10^{-3}$ to $10 \mathrm{~s}^{-1}$ and temperatures from $78 \mathrm{~K}$ to $500 \mathrm{~K}$ as well as Hopkinson bar tests at temperatures from $293 \mathrm{~K}$ to $700 \mathrm{~K}$. An example of the stress strain behaviour is illustrated in figure 1 . Having experimentally characterised the material he was able to construct a material algorithm, a modifed version of the ArmstrongZerilli model, that fitted the data over 7 orders of magnitude of strain rate and a temperature range of $600 \mathrm{~K}$. The resulting material algorithms for unshocked and shocked AQ85 are :

$$
\begin{aligned}
& \sigma-50+1130 e^{(-0.00515 \cdot 0.000262} \mathrm{lnc} c T+(1.13-0.00445 T) F(c) \\
& \text { Where } F(\epsilon)-357 \epsilon^{0} 52 \text { for unshocked A085 } \\
& F(\epsilon)-35 C+1.25 \epsilon^{0.34} \text { for shocked AQ85 } \\
& \text { with o(MPa) }
\end{aligned}
$$

Petit and co-researchers at Gramat ( ref 3 ) working with torsion test data, adopting a different approach, produced a modified Johnson Cook model to represent their experimental results for AQ85. Their resulting algorithms are :

$$
\begin{aligned}
& \sigma-2^{\prime} 72 \quad \epsilon^{0.088047}\left(1-\left(\frac{T}{1}-\frac{298}{513}\right)^{042}\right)+288\left(\epsilon+\epsilon_{c}\right)^{0.40245} \\
& \text { Where } \epsilon_{c}-0 \text { for unshocked AQ885 }
\end{aligned}
$$

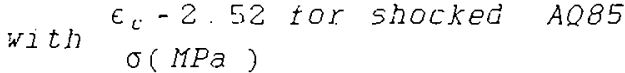

The available experimental data, however, is unable to identify which of these algorithms is more widly applicable to the deformation of AQ85. This arises because the high strain rate tensile and compression tests are integral tests in which work hardening and thermal softening effects cannot be isolated. 


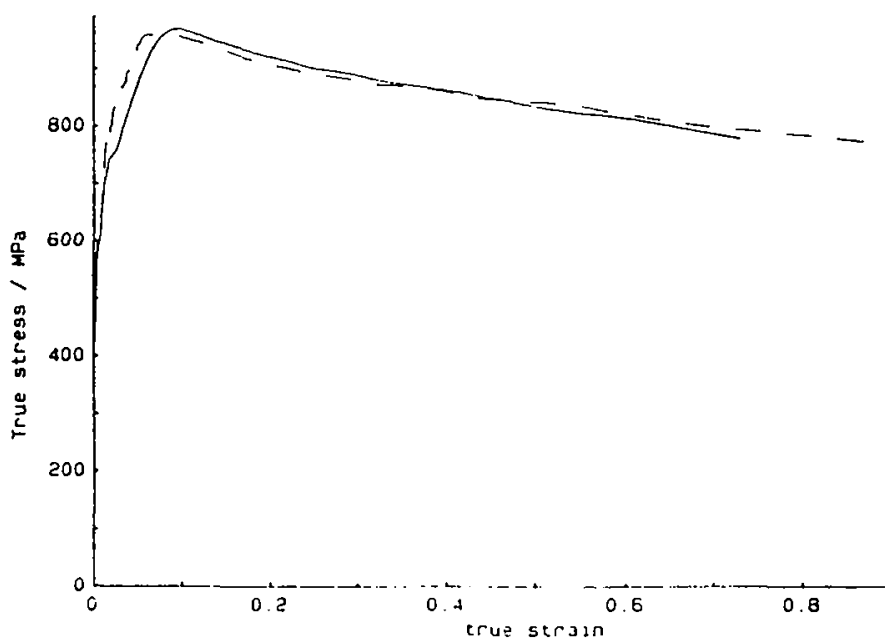

Figure 1 : Remko AQ85 (shocked) Experimental Stress - Strain Data

\subsection{Use of Hydrocodes in the Simulation of High Strain Rate Tests}

The simulation of the high strain rate material tests represents a powerful technique material research, since it allows the determination of the importance of work hardening and thermal effects during the test. It also permits the extrapolation limits to be identified before the model is used in complex warhead designs. An added benefit is that explosive phenomena, which introduce further complications, do not need to be simulated.

More importantly, however, initial test conditions can be identified that initiate a different mode of material response, which in turn can be used to distinguish between different algorithms.

Two main material tests have been simulated using the Lagrangian code DYNA2D. These are the miniature Compression Hopkinson Bar and the Tensile Hopkinson Bar.

By simulating these material tests we have been able not only to determine the range of applicibility of the algorithm to EFP design studies but also determine the validity of the assumptions made to interpret the test results eg constant strain rate, localisation of plastic deformation etc.

\subsection{Simulation of the Compression Hopkinson Bar}

The Miniature Compression Hopkinson Bar represents an impact problem where a $0.5 \mathrm{~mm}$ specimen, held on a fixed pressure bar, is impacted by a striker bar. The main output from the test is a dynamic stress/strain curve which includes work hardening, strain rate and thermal softening effects. The test cannot, therefore, be used to derive a constitutive relation, but does provide a stringent test of a model.

The requirements for the mesh configuration are relatively straightforward to ensure numerical stability in the simulation. The mesh used, however, needs to be fine enough to resolve stress wave propagation through the thickness of the specimen. The dynamic stress/strain behaviour can then computed directly from the calculation and compared with the experimental measurements.

The results for the room temperature unshocked/shocked AQ85, using both algorithms, are shown in figure 2. They illustrate that under conditions of low temperature and low strains, either model is applicable.

Simulating the test for shocked AQ85 at a start temperature of 473K, however, results in the dynamic stress/strain curves shown in figure 3 . Under these conditions the simulation has identified an appreciable difference between the predicted response using both models, even at low strains. Performing the test at this elevated temperature will, therefore, provide the necessary confirmation. 


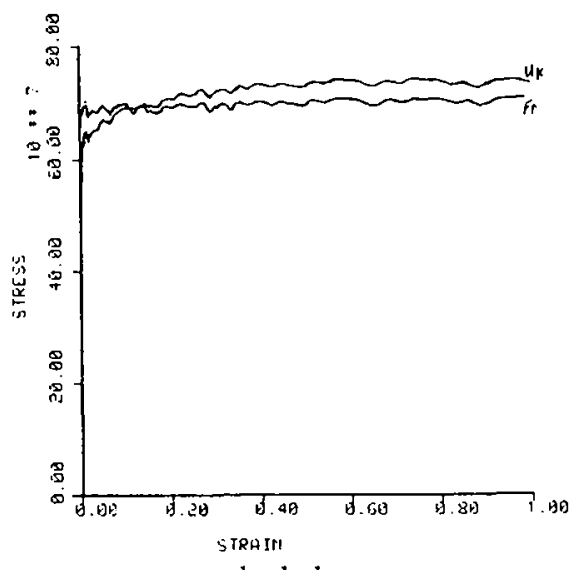

unshocked

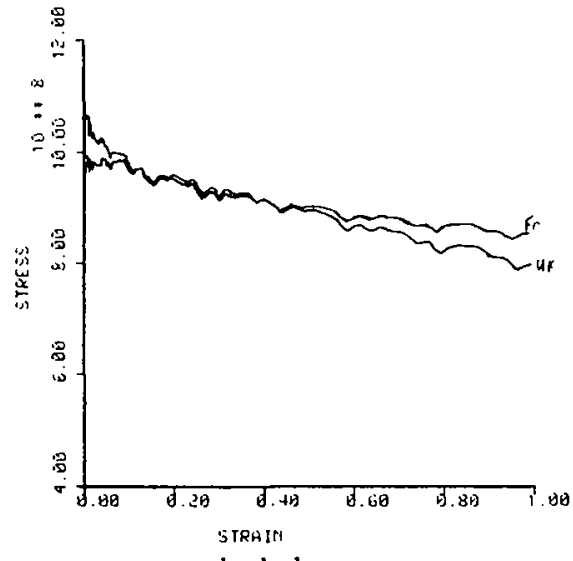

shocked

Figure 2 : Predicted Stress - Strain Behaviour for Remko AQ85

\subsection{Simulation of the Tensile Hopkinson Bar}

The Tensile Hopkinson Bar apparatus is much more complex requiring careful interpretation. The numerical simulation therefore, requires some simplification. The approach we have adopted models the dynamic loading on the specimen rather than the apparatus (ref 4 ). The simulation requires a very fine mesh in the guage length to resolve the detailed neck

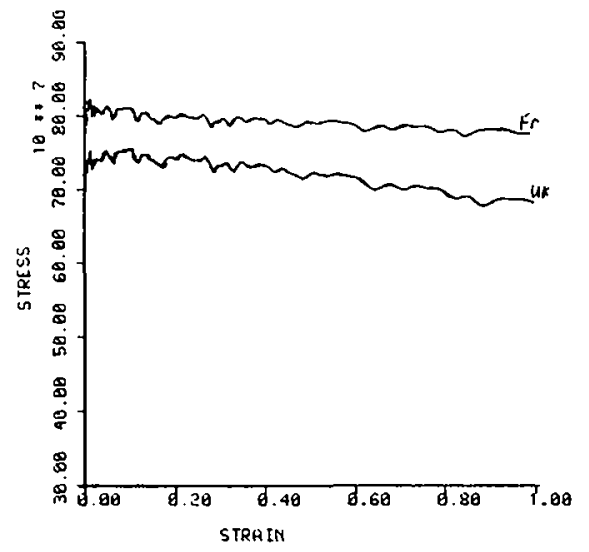

Figure 3 : Predicted behaviour for shocked AQ85 at 500K

formation. Under bigh strain rates the plastic strain in the neck can be 2-2.5 and the temperature can reach 700-800K. It is interesting to note these conditions are similar to those reached in explosively formed projectiles.

At room temperature the simulations of the tensile Hopkinson bar test predict identical deformation time histories for the specimen profile for both algorithms (figure 4). However, the predicted axial dynamic stress/strain behaviour, for both models, in the neck of the specimen, diverges rapidly (figure 5). This illustrates that the validity of a high strain rate constitutive relation must be determined in the high strain/high temperature regime. Performing the simulation with an increased start temperature of $300 \mathrm{~K}$ results in different specimen profiles, particularly in the region where the neck occurs. The simulation has thus identified a series of experimental studies that should unambiguously determine the range of applicability of various material algorithms. 




Figure 4 : Simulated Tensile Test

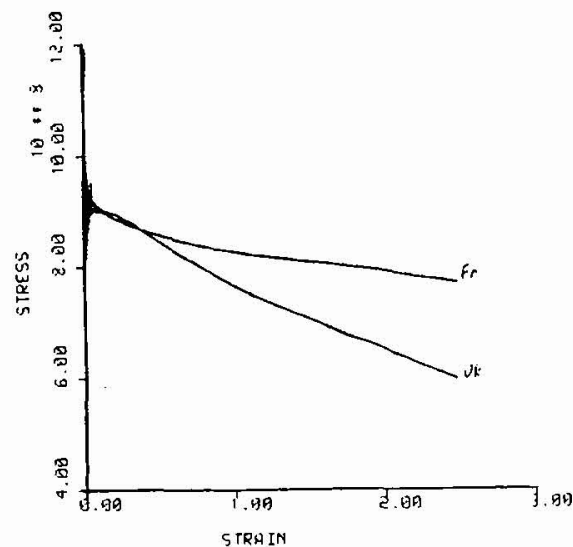

Figure 5 : Predicted behaviour Specimen Neck

\subsection{USE OF THE CODE IN SIMULATING EXPLOSIVELY FORMED PROJECTILES}

The code simulations described above have identified which material tests need to be performed in order to identify the accuracy of a particular constitutive relation. In addition the code has also highlighted the requirement to validate the constitutive relation at high strains and high temperatures. Explosively Formed Projectiles (EFPs) subject the material to these extreme deformation regimes and thus represent a stringent test of a constitutive relation. A successful material algorithm must therefore be able to predictively model various EFP designs.

As part of our IEPG research activities we have, with our European colleagues, carried out a detailed experimental and theoretical study of explosively formed projectiles with AQ85 liners. The experimental programme was divided so that each nation investigated the effect of various charge parameters on projectile characteristics (ref 5). In some instances the projectile was soft recovered for metallurgical analysis to characterise the structural condition of the material.

Having undertaken a rigorous study to identify the numerical problems associated with a simulation of the formation process using DYNA2D, a number of the design variants were simulated using the Goldthorpe model for AQ85. In performing these simulations the marked sensitivity of the specific heat of iron with temperature was included in the material specification. In addition the meshing of the liner was such that its residual temperature due to the passage of the shock was accurately reproduced. It should also be noted that since the algorithm has no abitary parameters within it the option to alter material properties in the simulations to achieve good agreement with experiment is not available. Failure to achieve good agreement with experiment then indicates inadequacies in the numerical scheme or other material deformation mechanisms not described by the algorithm.

\subsection{Results of EFP Simulations}

The EFP design parameters simulated were the effect of charge length, liner curvature, confinement, liner chamfer angle and a spherical EFP design. The profiles are shown in figure 6, compared with X-ray shadowgraphs.

In general the agreement with experiment is within $5 \%$, compared with $10 \%$ using previously published algorithms. Of more importance, however, for the first time we have been able to reproduce projectile characteristics for a wide range of charge designs using a single algorithm.

\subsection{Conclusions}

This paper has described the use of hydrocodes in simulating hoth laboratory material tests and the formation of explosively formed projectiles. It has demonstrated that the simulation of the laboratory material tests can yield considerable information on the deformation path and material condition in different parts of the test specimen. This can then be used not only to confirm the assumptions made in the analysis of the test, but also determine the extent to which the test data and its 


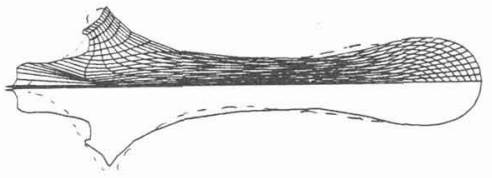

Liner radius $55 \mathrm{~mm}$

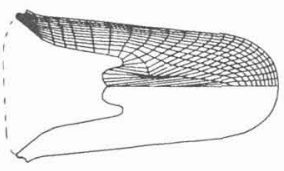

Liner radius $63.5 \mathrm{~mm} 3 \mathrm{deg}$ chamfer



Spherical Projectile

Experiment --...-

Figure 6 : Experimental v Predicted Projectile Profiles

associated material algorithm, can be extrapolated to more extreme states of deformation. Equally important hydrocode simulations can determine additional tests at different initial conditions for comparison of alternative material algorithms. Finally the paper has shown that provided the laboratory material tests used to derive material models are peformed on material in the relevant metallurgical condition, and subject it to relevant loading regimes, the resulting material algorithm can be used to predict explosively formed projectile characteristics.

\subsection{References}

1. R W Armstrong, F Zerilli, Jnl de Physique 49 C3-529 1988.

2. 'Constitutive Equations for Annealed and Explosively Shocked Iron for Application to High Strain Rates and Large Strains', B Goldthorpe, DYMAT Conference 1991, Strassbourg, France.

3. 'Thermomechanical Development of Iron Subjected to a Dynamic Stress Component', J Petit, P Hereil, J Sibeaud, 6th National Technical Meeting, DYMAT, Nov 1990.

4. 'A Numerical Study of the Tensile Test using DYNA2D', P Church, G Dobison, Oct 90, DRA Military Division, RARDE, UK.

5. 'The IEPG TA9.1 Phase II Experimental Firing Report', O Dullum, July 91, NDRE, Norway.

(C) British Crown Copyright 1991/MOD 